\title{
On Production Process Optimization Based on Queuing Theory-Take Enterprise A as an Example
}

\author{
Cai Gongshan ${ }^{1,2, *}$ Ni Yuan ${ }^{1,2}$ Yang Lu ${ }^{1,2}$ Gao Yudong ${ }^{1,2}$

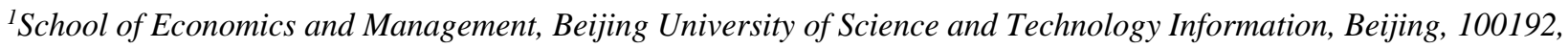 \\ China \\ ${ }^{2}$ Green Big Data Decision Making of Beijing Key Laboratory, Beijing, 100192, China \\ *Corresponding author. Email: 1033117679@qq.com
}

\begin{abstract}
In recent years, while the order-pull production model has been favored by the manufacturing industry, many companies also face problems such as order loss and insufficient production efficiency. In this paper, the method of process analysis is used to analyze the existing production process of Enterprise A, find out some problems in the entire production process, and then design an optimized production flow chart; then consider the service quality of the enterprise (the average of customers) Stay time), operating costs and the company's development plan draw two optimization strategies for company A. Using the queuing theory to compare and analyze the two optimization strategies, the research shows that the combination of process analysis and queuing theory can help solve the problems of high cost, low efficiency, and long service time.
\end{abstract}

Keywords: Queue theory, process analysis, process optimization, comparative analysis

\section{INTRODUCTION}

With the rapid development of today's global industrial technology, order-pull production is a major mode of modern manufacturing to pursue mass production and customized production, and it also has efficient and sensitive competitive advantages! With the demand for such customization growing rapidly, it is increasingly important for enterprises to shorten the delivery time of products. Therefore, many scholars have studied the processing sequencing problem of order production and the process optimization problem, which can be carried out from the following two aspects: first, the process analysis method based on industrial engineering. Process analysis refers to the basic material processing into finished products all assignments to decompose, this process clear operation properties of each processing step, sequence, the equipment used, and the consumed time and so on, in order to effectively use labor and equipment, to ensure the products to the fastest speed, lowest cost processing out [1]. Therefore, some scholars improve and optimize the production process through process analysis to reduce enterprise costs and customer waiting time and improve the company's production efficiency. For example, Zhang Xuelong [2] optimized and redesigned the processing plane layout and production process of GL's core products through process analysis, reducing the total number of processes by 7 , the distance of transportation by $74.9 \mathrm{~m}$, the number of workers by 5 , the time of stagnation by $138 \mathrm{~min}$, and the daily production capacity by 108 . Gao Liuyan and $\mathrm{Ma} \mathrm{HanWu} \mathrm{[3]} \mathrm{analyzed} \mathrm{the} \mathrm{working} \mathrm{procedure} \mathrm{of} \mathrm{the}$ rubber wheel production line of $\mathrm{T}$ plant with the value stream diagram tool, adopted simple automation to improve the value added ratio of each station, combined and recombined the working procedure through the man- machine mixed operation method to improve the process value added ratio, and then significantly improved the production efficiency and product quality of the plant. Huang et al. [4] carried out online measurement and error compensation on the surface of parts through process analysis and trigger detection, and realized adaptive flexible machining of thin-walled parts with due accuracy on a fiveaxis machine tool for the first time, thus improving the quality of products. Zhang Xinxin [5] compared and analyzed the differences between aluminum and steel production processes based on the structural characteristics of production processes in the existing aluminum industry, and pointed out the optimization and improvement measures of aluminum industry in the process. Second, based on the queuing theory model improvement and optimization. Scholars mainly focus on the make-to-order queue system, in which manufacturers need to adopt appropriate scheduling strategies to ensure the completion of scheduled products within the expected lead-time [6]. As delivery time and production cost emerge as a combined goal, manufacturers need to jointly consider cost, lead-time quotation, scheduling, and expediting policies when necessary. Scholars have conducted the following discussions on such issues. For example, So \& Song [7] studied the order loss, service rate and delivery time control strategy of the G/G/s order pull production queuing system under the constraint of the upper bound of delivery time probability. Maglaras [8] considered the dynamic pricing and prioritization of multi-class customers in the $\mathrm{M} / \mathrm{M} / 1$ queuing system. This paper adopted the approximate original markov decision process model. The research showed that pricing and scheduling policies could be decoupled after the transition stage. The decoupled pricing strategy only depends on the aggregate system load and the greedy c rule, which can minimize the instantaneous maintenance cost of the system. Wei Yingyuan[9], through 
the M/G/1 queuing model of Min (N, D) strategy, discussed the relationship between parameters in the model and steady-state captain distribution, and further demonstrated the important value of steady-state captain distribution expression in optimizing system capacity design.

To sum up, the pricing mechanism analysis based on the characteristics of "one-stop" service focuses on the classification and sorting of pricing strategies, which is the basis of pricing mechanism research. The pricing mechanism analysis based on bilateral market focuses on the selection of optimal pricing model under different situations, which is the core of pricing mechanism research. The two studies support each other and complement each other. Based on this, this paper firstly optimized the production process of enterprise A through process analysis, and proposed optimization strategies considering the delivery time and waiting cost of enterprise A. Secondly, after the process optimization mathematical model is set up based on queuing theory analysis of the different strategies when waiting for captain, customers stay time and related parameters, such as the loss for the enterprise to provide the reference opinion, in order to improve the production efficiency, reduce waste, reduce inventory, increase production capacity, thereby enhancing the market demand diversity, the fitness of improve the core competitiveness of enterprises [10].

\section{BACKGROUND}

\subsection{Enterprise Status of $A$}

A enterprise is the supplier Foxconn, now the main mobile phone cover production business has two production lines, mainly includes the following steps: first phone in building C complete forming, early check, the cut is expected to top process, and then moving to the D floor for baking, stained with dirt, post blue white protective film, protective film and copying milling process, handling to the $\mathrm{C}$ floor again for CNC process, and then will complete the cutting nozzle parts handling to the $\mathrm{D}$ floor, burnish, wipe the dirt as well as the whole packing and so on nearly 20 multi-channel process. Headquartered in Shen Zhen, the company has a high inventory cost. It is known that the inventory capacity of the factory is about 10000. Main business from Foxconn or some similar orders, but because of the fierce competition in the market now, fixed orders, customers have been few and far between, most orders are not fixed, so when the order suddenly focus to reach the ceiling of the enterprise, queuing phenomenon will be aggravated, wait for customer dissatisfaction which leads to customer satisfaction will be reduced, serious and even order loss [11].

\subsection{Production Process Analysis of A Enterprise}

Process analysis is a detailed analysis of the entire manufacturing process of products and parts, especially for the analysis of hidden costs and wastes such as handling, storage and waiting. After data recording and analysis of the production process of the enterprise, the production process diagram of the mobile phone cover can be obtained as shown in figure 1 below.

\begin{tabular}{|c|c|c|c|c|c|c|c|c|}
\hline Department: & \multirow{2}{*}{\multicolumn{2}{|c|}{$\begin{array}{l}\text { Serial Number: } \\
\text { Serial Number: }\end{array}$}} & \multicolumn{6}{|c|}{ Statistical } \\
\hline Work Title: & & & \multicolumn{2}{|l|}{ Project } & Freq & \multicolumn{2}{|c|}{ Time $/ \mathrm{s}$} & \multirow[t]{2}{*}{ Distance } \\
\hline \multicolumn{3}{|l|}{ Start: } & \multicolumn{2}{|c|}{ Process 0} & 11 & \multicolumn{2}{|c|}{7604.7} & \\
\hline \multicolumn{3}{|l|}{ Researcher: } & \multicolumn{2}{|c|}{ Check $\square$} & 2 & \multicolumn{2}{|c|}{45} & \\
\hline \multicolumn{3}{|l|}{ Reviewer: } & \multicolumn{2}{|c|}{ Carry $\rightarrow$} & 5 & \multicolumn{2}{|c|}{3383} & 233 \\
\hline \multicolumn{3}{|l|}{ Date: } & \multicolumn{2}{|c|}{ Wait D } & 0 & \multicolumn{2}{|c|}{0} & \\
\hline \multicolumn{3}{|l|}{ Date: } & \multicolumn{2}{|c|}{ Storage $\nabla$} & 5 & \multicolumn{2}{|c|}{2720} & \multirow{3}{*}{ Note } \\
\hline \multirow{2}{*}{ Job Description } & \multirow{2}{*}{$\begin{array}{c}\begin{array}{c}\text { Distance } \\
/ \mathrm{m}\end{array} \\
\end{array}$} & \multirow{2}{*}{$\begin{array}{c}\text { Time } \\
/ \mathrm{s}\end{array}$} & \multicolumn{5}{|c|}{ Process series } & \\
\hline & & & Process & Check & Cany & Wait & \begin{tabular}{|l|} 
Storage \\
\end{tabular} & \\
\hline 1. Calender & & 33.2 & a & $\square$ & $\rightarrow$ & D & V & 1 \\
\hline 2. Initial check & & 16 & 0 & 早 & $\rightarrow$ & D & $\nabla$ & 1 \\
\hline 3. Cut material & & 15 & $0<$ & $\square$ & $\rightarrow$ & D & $\nabla$ & 1 \\
\hline 4. Preserve & & 720 & 0 & $\square$ & $\rightarrow$ & $D$ & 7 & \\
\hline 5. Transport & 77 & 1160 & 0 & $\square$ & $\longrightarrow$ & D & $\nabla$ & 1 \\
\hline 6. Bake & & 7200 & $0<$ & $\square$ & $\rightarrow$ & D & $\nabla$ & 1 \\
\hline 7. Transport & 4 & 17 & 0 & $\square$ & $\rightarrow$ & D & $\nabla$ & 1 \\
\hline 8. Adhering dirt & & 10 & 9 & $\square$ & $\rightarrow$ & D & $\nabla$ & 1 \\
\hline 9. Stick a white film & & 12 & 9 & $\square$ & $\rightarrow$ & D & $\nabla$ & 1 \\
\hline 10. Stick a blue film & & 13.5 & $a$ & $\square$ & $\rightarrow$ & D & $\nabla$ & 1 \\
\hline 11. Transport & 8 & 46 & 0 & $\square$ & $\rightarrow$ & D & $\nabla$ & 1 \\
\hline 12. Wash material & & 29 & 9 & DI & $\rightarrow$ & D & $\nabla$ & 1 \\
\hline 13. Preserve & & 900 & 0 & $\square$ & $\rightarrow$ & D & $\theta$ & \\
\hline 14. Transport & 72 & 1080 & 0 & $\square$ & $\longrightarrow$ & D & $\bar{\nabla}$ & 1 \\
\hline 15. CNC & & 121 & $0=$ & 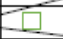 & $\rightarrow$ & D & $\nabla$ & 4 \\
\hline 16. Preserve & & 1100 & 0 & $\square$ & $\rightarrow$ & D & 7 & \\
\hline 17. Transport & 72 & 1080 & 0 & $\square$ & $\longrightarrow$ & D & $\nabla$ & 1 \\
\hline 18. Cutting nozzle & & 36 & 9 & $\square$ & $\rightarrow$ & D & $\nabla$ & 2 \\
\hline 19. Polishing & & 105 & 9 & $\square$ & $\rightarrow$ & D & $\nabla$ & 6 \\
\hline 20. Wipe the dirt & & 30 & a & $\square$ & $\rightarrow$ & D & $\nabla$ & 1 \\
\hline 21. Final inspection & & 29 & 0 & $\mathbf{E}$ & $\rightarrow$ & D & $\nabla$ & 1 \\
\hline 22. Preserve & & & 0 & $\square$ & $\rightarrow$ & D & 7 & \\
\hline 23. Preserve & & & 0 & $\square$ & $\rightarrow$ & D & 7 & \\
\hline Total & 233 & 13752.7 & 11 & 2 & 5 & 0 & 5 & \\
\hline
\end{tabular}

Figure 1 mobile phone cover production process diagram

\subsection{Problems in the production process of company $A$}

(1) the carrying distance is too long. It can be seen from figure 3.1 that parts are transported back and forth between building $\mathrm{C}$ and building $\mathrm{D}$, and there are also transportation situations between each process in the two buildings. This results in excessive handling times and long handling paths. In the whole production process, the handling distance is as long as 233 meters.

(2) there is artificial waste. These three processes are simple and closely related, and the processes of sticking white film and blue film are basically the same. Each station occupies one worker, resulting in artificial waste. And by 
understanding copying milling on the phone cover is not much use.

\section{OPTIMIZATION ANALYSIS}

\subsection{Production process optimization strategy of A company}

Through the analysis of the production process, the working procedure in building $\mathrm{D}$ can be moved to building $\mathrm{C}$, directly reducing the distance between the two buildings of parts $\mathrm{C}$ and $\mathrm{D}$, and shortening the carrying distance of parts caused by the scattered layout of the original working procedure in the building. And the combination of smudges, white film, iron and blue film these three processes, at the same time to cancel the copying milling process. In this way, the optimized production process procedure is shown in figure 2 .

\begin{tabular}{|c|c|c|c|c|c|c|c|c|}
\hline Department: & \multirow{2}{*}{\multicolumn{2}{|c|}{$\begin{array}{l}\text { Serial Number: } \\
\text { Serial Number: }\end{array}$}} & \multicolumn{6}{|c|}{ Statistical } \\
\hline Work Title: & & & \multicolumn{2}{|c|}{ Project } & Freq & \multicolumn{2}{|c|}{ Time $/ \mathrm{s}$} & Distance \\
\hline \multicolumn{3}{|l|}{ Start: } & \multicolumn{2}{|c|}{ Process 0} & 8 & \multicolumn{2}{|c|}{7604.7} & \\
\hline \multicolumn{3}{|l|}{ Researcher: } & \multicolumn{2}{|c|}{ Check $\square$} & 2 & \multicolumn{2}{|c|}{45} & \\
\hline \multicolumn{3}{|l|}{ Reviewer: } & \multicolumn{2}{|c|}{ Carry $\longrightarrow$} & 3 & \multicolumn{2}{|c|}{29} & 24 \\
\hline \multicolumn{3}{|l|}{ Date: } & \multicolumn{2}{|c|}{ Wait D } & 0 & \multicolumn{2}{|c|}{0} & \\
\hline \multicolumn{3}{|l|}{ Date: } & \multicolumn{2}{|c|}{ Storage $\nabla$} & 1 & \multirow{2}{*}{\multicolumn{2}{|c|}{0}} & \multirow{3}{*}{ Note } \\
\hline \multirow{2}{*}{ Job Description } & Distance & Time & \multicolumn{3}{|c|}{ Process Series } & & & \\
\hline & $/ \mathrm{m}$ & /s & Process & Check & Cary & Wait & Storage & \\
\hline 1. Molding & & 33.2 & a & $\square$ & $\rightarrow$ & D & $\nabla$ & 1 \\
\hline 2. Initial check & & 16 & 0 & Z & $\rightarrow$ & D & $\nabla$ & 1 \\
\hline 3. Cut material & & 15 & - & $\square$ & $\rightarrow$ & D & $\nabla$ & 1 \\
\hline 4. Bake & & 7200 & a & $\square$ & $\rightarrow$ & D & $\nabla$ & 1 \\
\hline 5. Transport & 4 & 17 & 0 & $\square$ & $\Rightarrow$ & D & $\nabla$ & 1 \\
\hline 6. Stick film & & 12 & 2 & $\square$ & $\rightarrow$ & D & $\nabla$ & 2 \\
\hline 7. Transport & 8 & 46 & 0 & $\square$ & $\Longrightarrow$ & D & $\nabla$ & 1 \\
\hline 8.CNC & & 121 & - & $\square$ & $\rightarrow$ & D & $\nabla$ & 4 \\
\hline 9. Transport & 72 & 1080 & 0 & $\square$ & $\Rightarrow$ & D & $\nabla$ & 1 \\
\hline 10. Cutting nozzle & & 36 & 9 & $\square$ & $\rightarrow$ & D & $\nabla$ & 2 \\
\hline 11. Polishing & & 105 & 0 & $\square$ & $\rightarrow$ & D & $\nabla$ & 6 \\
\hline 12. Wipe the dirt & & 30 & a & $\square$ & $\rightarrow$ & D & $\nabla$ & 1 \\
\hline 13. Final inspection & & 29 & 0 & E & $\longrightarrow$ & D & $\nabla$ & 1 \\
\hline 14. Preserve & & & 0 & $\square$ & $\rightarrow$ & D & V & \\
\hline Total & 24 & 7635.2 & 8 & 2 & 3 & 0 & 1 & \\
\hline
\end{tabular}

Figure 2 mobile phone cover production process diagram

However, as most orders are unstable and unstable, when the orders suddenly reach the upper limit of the enterprise, the enterprise will delay the delivery date of orders or reject some of them, which will lead to dissatisfaction of these customers and lead to a decline in customer satisfaction rate, or even loss of orders. So consider adding another line. Two optimization strategies can be obtained by optimizing the production process of the enterprise and analyzing the problems at present. First, analyze and optimize the original production process; Build the same production line on the basis of the above to reduce customer waiting time, reduce the loss caused by the loss of orders to the company.

\subsection{Construct the queuing theory analysis model of production process optimization}

\subsubsection{Model selection of queuing theory}

In real life, customers often complain about waiting in line, but in daily life, they often encounter the phenomenon of queuing, such as customers to buy goods at the mall, patients to the hospital, cars to gas stations, ships to dock at the port, telephone booking tickets and so on. How to effectively solve the queuing problem? People put forward the theory of queuing. Queuing theory, also known as random service theory, is a mathematical theory and method to study queuing system. Specifically, on the basis of studying the probabilistic regularity of various queuing systems, the optimal design and optimal operation of queuing systems are solved [12]. The queuing service process can be described as follows: firstly, starting from the customer source, waiting in line to receive the service before arriving at the service agency, and leaving after the service is completed [13]. The service system model of queuing theory is generally shown in figure 3 .

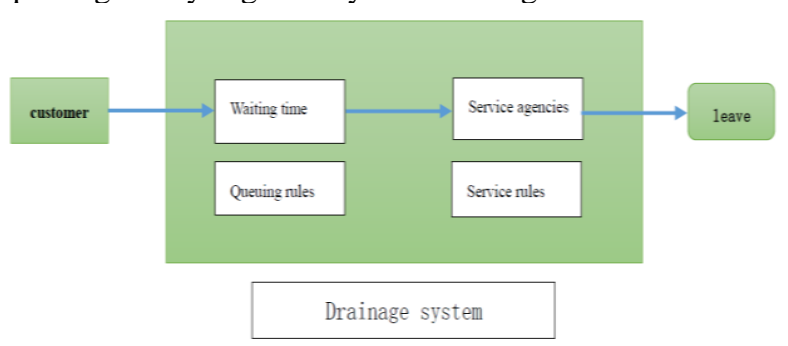

Figure 3 service system model diagram

The actual situation of company A has been introduced in detail above. The factory of this enterprise has 2 production lines, each of which has more than 20 working procedures. Each working procedure corresponds to one or more workers, and the time difference of each working procedure is relatively large. Because the inventory capacity is limited by the actual situation of the enterprise, it is impossible to be infinite. It is understood that the inventory capacity of this enterprise is about 10000 . According to the existing situation of the enterprise, it can be seen that the enterprise is suitable for establishing the model of system capacity and limited service organization, so the queuing model of $\mathrm{M} / \mathrm{M} / 2 / 10000$ can be selected, as shown in figure 4 below.

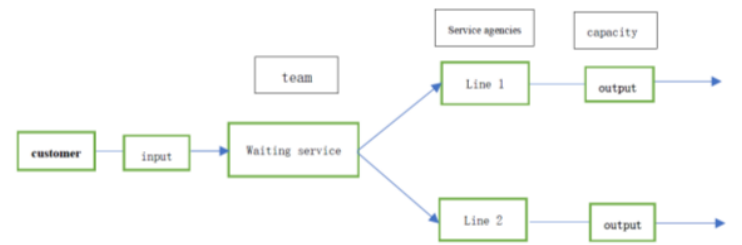

Figure 4 M/M/2/10000 service system model diagram 


\subsubsection{Model assumption}

Through the basic understanding of the above queuing theory, it can be seen that the general queuing system has three basic components [14]: (1) input process. Input process refers to the process of customers entering the queuing system, which mainly includes the following three elements: customer source capacity, customer arrival mode and customer arrival time distribution.; (2) queuing rules. Queuing rules mainly refer to the order in which customers receive services after entering the queuing system. Most of them can be divided into three categories, namely instant system, waiting system and mixed system; (3) service process. From the service work and the number of service agencies, there are three types of service agencies, the number of receiving services and the distribution of service time.to facilitate the discussion of the queuing theory model established later, the parameters required in the queuing theory model are summarized as follows: 1 .

Table 1 statistics of parameters of queuing theory model

\begin{tabular}{cl}
\hline Symbol & Express meaning \\
\hline$\lambda$ & Mean arrival rate \\
$1 / \lambda$ & Mean arrival interval \\
$\mu$ & Mean service rate \\
$1 / \mu$ & Average service time per customer \\
$\mathrm{S}$ & Number of service counters \\
$\rho$ & The average load \\
$P_{j}$ & The probability of $\mathrm{j} \quad$ customers $\quad$ at \\
$D$ & Thuilibrium probability that the customer waits \\
$Q$ & Busy period \\
$\mathrm{L}$ & Captain's expectations \\
$L_{q}$ & Wait for the captain's expectations \\
$W$ & Expected length of stay $[15]$ \\
$W_{q}$ & Expected waiting time \\
$\lambda_{e}$ & Effective arrival rate \\
$W=W_{q}+\frac{1}{u} ; \quad$ Litter: $L_{q}=\lambda_{e} W_{q} ; L=\lambda_{e} W$ \\
\hline
\end{tabular}

Customers: since there are no real customers in the model, the orders arriving at the enterprise every day are abstractly replaced in this model, and each order of mobile phone cover represents each customer; Service organization: the service organization is the production equipment in the whole production process, and the whole production process has a relatively stable production tempo, output and quality. Company A has two production lines, and each production line has more than 20 processes, and each process needs one or more workers to manage; Queuing rules: this model should have a first-come-first-served queuing rule. In order to meet the timely delivery of customers' orders, enterprises must adopt the first-comefirst-served rule [16]; Arrival process: the arrival process is the process that the customer's order arrives at the enterprise. The arrival time and quantity of the customer order in the enterprise will be attached later in this paper; System capacity: since the warehouse space of the enterprise cannot be infinite, it is understood that the inventory capacity of the enterprise is 10000.According to the corresponding relationship above, the queuing model of $\mathrm{M} / \mathrm{M} / 2 / 10000$ can be established by using the queuing theory. Here is an introduction to the relationship between these parameters in the model.

Let $p=\lambda / s u$.The steady-state probability of the system.

$P_{0}=\left[\sum_{i=0}^{S-1} \frac{(S \rho)^{i}}{i !}+\sum_{i=S}^{k} \frac{S^{S} \rho^{i}}{S !}\right]^{-1}$

$P_{j}=\left\{\begin{array}{l}\frac{(S \rho)^{j}}{j !} P_{0}, j=1,2, \ldots, \quad \mathrm{S} \\ \frac{{ }_{S} S^{j} j}{S !} P_{0}, j=S+1, \ldots, \quad k\end{array}\right.$

It is clear to see the probability of the service system rejecting a customer, also known as the loss rate.

By definition: $\mathrm{L}=\sum_{j=0}^{k} \mathrm{j} \mathrm{P}_{j}$

$L_{q}=\sum_{j=0}^{k-S} \mathrm{jP}_{S+j}=\sum_{j=S}^{k}(j-S) P_{j}$

$L_{q}=\frac{\rho(S \rho)^{S} P_{0}}{S !(1-\rho)^{2}}\left[1-\rho^{k-S}-(k-S) \rho^{k-S}(1-\rho)\right]$

It can be verified that: $L=L_{q}+S \rho\left(1-P_{k}\right)$

Clearly the probability that the customer can both arrive and enter the service system is $1-P_{k}$, So the effective rate of service delivery $\lambda_{e}=\lambda\left(1-P_{k}\right)$, available:

$\lambda_{e}=\mu\left[S-\sum_{j=0}^{S-1}(S-j) P_{j}\right]$

Use the grain formula: $W_{q}=\frac{L_{q}}{\lambda\left(1-P_{k}\right)} ; W=\frac{L}{\lambda\left(1-P_{k}\right)}$

\subsubsection{Model solution}

Of course, some data are needed to solve the model. The following is the daily orders received by the company in one week in January this year, as shown in table 2. Through statistics and analysis in table 2 at the same time the arrival of the order date will find order way is according to the poisson distribution, which is the model of customer based on poisson distribution way to arrive at the service. 
Table 2 Order statistics table

\begin{tabular}{|c|c|c|c|c|c|}
\hline$\overline{\text { Order Date }}$ & Amount & Type & Order Date & Amount & Type \\
\hline 2018010201 & 230 & S2-1029B-Z021F & 2018010504 & 850 & S2-10228-R0002 \\
\hline 2018010202 & 400 & S2-10220-A9326 & 2018010505 & 1350 & S2-1019H-A0037 \\
\hline 2018010203 & 2000 & S2-1019P-A9320 & 2018010506 & 1700 & S2-1019H-A0030 \\
\hline 2018010204 & 3000 & S2-1019B-F000D & 2018010507 & 900 & S2-1019H-A0F01 \\
\hline 2018010205 & 1000 & S2-1019H-A0036 & 2018010601 & 1100 & S2-1040S \\
\hline 2018010206 & 160 & S2-1023P-C000S & 2018010602 & 750 & S2-1019H-A0030 \\
\hline 2018010207 & 50 & S2-10219-E0J05 & 2018010603 & 1300 & S2-1769H-G0030 \\
\hline 2018010301 & 100 & S2-1019H-A0030 & 2018010704 & 200 & S2-1019P-A960B \\
\hline 2018010302 & 260 & S2-1019H-A0030 & 2018010705 & 800 & S2-1019B-F000G \\
\hline 2018010303 & 506 & S2-1023P-C000N & 2018010706 & 180 & S2-1019P-A960B \\
\hline 2018010304 & 1100 & S2-1019B-F000D & 2018010707 & 700 & S2-1019H-A003 \\
\hline 2018010305 & 2100 & S2-10228-R0005 & 2018010708 & 1750 & S2-1063H-G003 \\
\hline 2018010306 & 2400 & S2-1019H-A0030 & 2018010701 & 1650 & S2-1016M-V00F \\
\hline 2018010307 & 1350 & S2-10264-H002G & 2018010702 & 800 & S2-10267-J000F \\
\hline 2018010308 & 800 & S2-1019B-F000G & 2018010703 & 1088 & S2-10219-E0J05 \\
\hline 2018010309 & 302 & S2-1023P-C000N & 2018010704 & 1500 & S2-1019H-A003 \\
\hline 2018010310 & 240 & S2-10219-E0J05 & 2018010705 & 500 & S2-1019P-A9320 \\
\hline 2018010311 & 60 & S2-1019P-A0030 & 2018010801 & 85 & S2-1619P-G790 \\
\hline 2018010401 & 160 & S2-1019P-A960B & 2018010802 & 340 & S2-1025L-N0KH \\
\hline 2018010402 & 500 & S2-1019B-F000D & 2018010803 & 550 & S2-1028W-Z021 \\
\hline 2018010403 & 1200 & S2-10267-J000F & 2018010804 & 840 & S2-1016M-V00F \\
\hline 2018010404 & 1450 & S2-1019P-A0030 & 2018010805 & 1120 & S2-10219-E0J05 \\
\hline 2018010405 & 900 & S2-1029B-Z021N & 2018010806 & 2260 & S2-1023P-C000S \\
\hline 2018010406 & 650 & S2-1019P-A9320 & 2018010807 & 1400 & S2-10220-A9326 \\
\hline 2018010407 & 340 & S2-1019P-A0030 & 2018010808 & 906 & S2-1023L-G0005 \\
\hline 2018010408 & 90 & S2-1028W-Z0213 & 2018010809 & 404 & S2-1023P-C00N \\
\hline 2018010501 & 450 & S2-1021P-N0K1A & 2018010810 & 260 & S2-1019B-F001G \\
\hline 2018010502 & 500 & S2-1019B-F000D & 2018010811 & 100 & S2-10219-E0J05 \\
\hline 2018010503 & 150 & S2-1023H-G0003 & & & \\
\hline
\end{tabular}


The statistical results of service hours are shown in table 3. According to the statistical table of service timing, it can be found that orders are distributed according to negative index every day.

Table 3 Service hours statistics

\begin{tabular}{|l|c|c|c|c|c|}
\hline Service time/s & $(0,10]$ & $(10,20]$ & $(20,30]$ & $(30,40]$ & $(40,50]$ \\
\hline Number of customers & 350 & 235 & 160 & 104 & 62 \\
\hline Service time/s & $(50,60]$ & $(60,70]$ & $(70,80]$ & $(80,90]$ & $(90,100]$ \\
\hline Number of customers & 40 & 21 & 12 & 7 & 5 \\
\hline Service time/s & $(110,120]$ & $(120,130]$ & & & \\
\hline Number of customers & 3 & 1 & & & \\
\hline
\end{tabular}

According to the data in table 2 and table 3, the parameters needed to establish this model are calculated.

(1) average arrival rate $\lambda$

First calculate the average arrival rate for each day (customer/hour), then calculate the average arrival rate for the whole week (customer/hour)

$\lambda_{1}=\frac{230+400+2000+3000+1000+160+50}{24}=285$

$\lambda_{2}=\frac{100+260+506+1100+2100+2400+1350+800+302+240+60}{24}$

$=384$

$\lambda_{3}=\frac{160+500+1200+1450+900+650+340+90}{24}=220$

$\lambda_{5}=\frac{450+500+150+850+1350+1700+900+1100+750+1300}{24}=377$

$\lambda_{6}=\frac{200+800+180+700+1750+1650+800+1088+1500+500}{24}=382$

$\lambda_{7}=\frac{85+340+550+840+1120+2260+1400+906+404+260+100}{24}=344$

Combined with the above, the average arrival rate of a week can be obtained:

$\lambda=\frac{\lambda_{1}+\lambda_{2}+\lambda_{3}+\lambda_{4}+\lambda_{5}+\lambda_{6}+\lambda_{7}}{7}$

$=\frac{285+384+220+247+377+382+344}{7}$

$=320$

(2) ean service rate $\mu$

First, calculate the total time spent on serving customers every day. Of course, for the convenience of calculation, take the median value in each interval as the average value within the interval, and then divide by the total number of people in a day to get:

$$
\begin{aligned}
\frac{1}{\mu}=\frac{350 \times 5+235 \times 15+\ldots+115 \times 3+125 \times 1}{350+235+\cdots+1} \\
=21.71 \text { (seconds/customer) } \\
=0.36 \text { (Minutes/customer) }
\end{aligned}
$$

$\mu=0.046$ (seconds $/$ customer $)=2.8$ (Minutes $/$ customer $)$

$\lambda=320($ Customers $/$ hour $)=5.3$ (Minutes $/$ customer $)$

$\rho=\frac{\lambda}{S \mu}=\frac{5.3}{2 * 2.8}=0.95$

The probability that an order can be served without waiting is obtained from formula (1)

$$
\begin{aligned}
& P_{0}=\left[\sum_{i=0}^{S-1} \frac{(S \rho)^{i}}{i !}+\sum_{i=S}^{k} \frac{S^{S} \rho^{i}}{S !}\right]^{-1} \\
& =\left[\sum_{i=0}^{2-1} \frac{(2 * 0.95)^{i}}{i !}+\sum_{i=2}^{10000} \frac{2^{2} 0.95^{i}}{2 !}\right]^{-1} \\
& =\left[\sum_{i=0}^{1} \frac{(1.9)^{i}}{i !}+2 \sum_{i=2}^{10000}(0.95)^{i}\right]^{-1} \\
& =(1.9+13.2)^{-1} \\
& =0.07
\end{aligned}
$$

$P_{1}=S \rho P_{0}=2 \times 0.95 \times 0.07=0.133$

$P_{0}+\mathrm{P}_{1}=0.07+0.133=0.203$

That is, the probability that customers can receive services immediately without waiting is 0.203 . Since $0.203<1$, there must be customers waiting for services in this factory. 
$=\left[\sum_{i=0}^{1} \frac{(2 \times 0.88)^{i}}{i !}+\sum_{i=2}^{10000} \frac{2^{2} *(0.88)^{i}}{2 !}\right]^{-1}$

$=0.1$

$P_{1}^{1}=S \rho^{1} P_{0}^{1}=2 \times 0.88 \times 0.1=0.176$

The expectation of waiting captain can be obtained:

$L_{q}{ }^{1}=\frac{\rho(S \rho)^{S} P_{0}{ }^{*}}{S !(1-\rho)^{2}}\left[1-\rho^{k-S}-(k-S) \rho^{k-S}(1-\rho)\right]$

$\lambda_{e}=\mu\left[S-\sum_{j=0}^{S-1}(S-j) P_{j}\right]=\mu\left(\mathrm{S}-2 \mathrm{P}_{0}-\mathrm{P}_{1}\right)$

$=2.8(2-2 \times 0.07-0.133)=4.8$

The average length can be obtained from formula (5) :

$\mathrm{L}=\mathrm{L}_{q}+\mathrm{S}-2 \mathrm{P}_{0}-\mathrm{P}_{1}=48-2 \times 0.07-0.133=47.727$

The average length of stay of customers:

$\mathrm{W}=\frac{L}{\lambda_{e}}=\frac{47.7}{4.8}=9.94$ (minutes)

Calculate the value of loss due to customer waiting before optimization:

$V_{0}=\mathrm{L}_{q} \times 24 \times 60 \times 1=69120$ (yuan)

After the optimization of the production process, the arrival state of orders, that is, the arrival situation of customers, was not changed, but the production efficiency and service quality of enterprises were improved, mainly reflected in shortening the production cycle and customer waiting time, so the important parameters in this model were not changed, only the value of $\backslash \mathrm{mu}$ was changed. Therefore, the model of strategy 1 is still $\mathrm{M} / \mathrm{M} / 2 / 10000$, so the optimized parameter value will be calculated. As the specific data in figure 3.1 in chapter 3 above is compared with figure 4.1 after process optimization in chapter 4 , it can be seen that the optimized time of a mobile phone covering the whole process is shortened by 6117.5 seconds. Thus, each customer is served nearly 102 minutes in advance. Through simple calculation, it can be seen that the number of customers that can be served more than once in 102 minutes after optimization is $102 / 0.36=283$ (bits), that is, 283 more customers can be served every day. Then, after optimization:

$\mu=2.8+\frac{283}{24 * 60}=3$ (customer $\left./ \mathrm{min}\right)$

$\lambda=5.3($ customer $/ \mathrm{min})$

$\rho^{1}=\frac{\lambda}{S \mu}=\frac{5.3}{2 \times 3}=0.88$

$P_{0}{ }^{1}=\left[\sum_{i=0}^{S-1} \frac{(S \rho)^{i}}{i !}+\sum_{i=S}^{k} \frac{S^{S} \rho^{i}}{S !}\right]^{-1}$

$$
\begin{gathered}
=\frac{0.88 \times(2 \times 0.88)^{2} \times P_{0}}{2 ! \times(1-0.88)^{2}}\left[1-0.88^{10000-2}-(10000-2) * 0.88^{10000-2}(1\right. \\
-0.88)]
\end{gathered}
$$

$\approx 9.5$

The average captain: $\mathrm{L}=\mathrm{L}_{q}^{1}+\mathrm{S}-2 \mathrm{P}_{0}^{1}-\mathrm{P}_{1}^{1}=11.12$

$\lambda_{\mathrm{e}}^{1}=\mu\left[S-\sum_{\mathrm{j}=0}^{\mathrm{S}-1}(\mathrm{~S}-\mathrm{j}) \mathrm{P}_{\mathrm{j}}\right]=\mu\left(\mathrm{S}-2 \mathrm{P}_{0}^{1}-\mathrm{P}_{1}^{1}\right)=4.872$

Strategy 1 average customer wait time:

$\mathrm{W}=\frac{L}{\lambda_{e}^{1}}=\frac{11.124}{4.8}=2.28$ (minutes)

Loss value due to customer waiting in strategy 1 : $V_{1}=\mathrm{L}_{q}^{1} \times 24 \times 60 \times 1=13680$ (yuan)

On the basis of optimization, strategy 2 adds an assembly line, so the model in the queuing theory becomes $\mathrm{M} / \mathrm{M} / 3 / 10000$, so the following calculation is also based on the above. Here are some important parameters in strategy 2:

The first order the $S=3$;

$\rho^{2}=\frac{\lambda}{S \mu}=\frac{5.3}{3 \times 3}=0.58$

$P_{0}^{2}=\left[\sum_{i=0}^{S-1} \frac{(S \rho)^{i}}{i !}+\sum_{i=S}^{k} \frac{S^{S} \rho^{i}}{S !}\right]^{-1}$

$=\left[\sum_{i=0}^{2} \frac{(3 * 0.58)^{i}}{i !}+\sum_{i=3}^{10000} \frac{3^{3} *(0.58)^{i}}{3 !}\right]^{-1}$

$=0.16$

$P_{j}=\frac{(S \rho)^{j}}{j !} P_{0}$

$P_{1}^{2}=S \rho^{2} P_{0}^{2}=0.28$

$P_{2}^{2}=\frac{\left(S \rho^{2}\right)^{2}}{2 !} P_{0}^{2}=0.24$ 
and activities. But strategy two added a production line compared with strategy one, with the survey finding that adding a production line would require an investment of about 15 million yuan. From this, a relatively simple calculation can be made, $1500 / 398=3.8$ (years), that is, the investment can be recovered in nearly 4 years. After investigation, it is found that the machine life of this kind of production line is the least 7 years. Therefore, if the future development is in accordance with this situation, the profit can be made in the last three years in the future. However, the average stay time of strategy 2 customers is 0.43 minutes, compared with 2.28 minutes in strategy 1 , the waiting time is reduced, which improves the service quality of the enterprise.

Through the analysis of the two strategies, it can be seen that if managers are more optimistic about this industry or want to expand the development of strategy two; Managers who are not optimistic about the future development of the industry or who are more conservative can choose strategy on.

\section{ACKNOWLEDGMENT}

This work was supported by National key research and development program (2017YFB1400400), Beijing youth top talent cultivation program (CIT\&TCD20180405), QinXin talent program (QXTCPC201706).

\section{REFERENCES}

optimization strategy, and in the queue model is the most important parameters in the customer's average stay and wait for the captain's expectations, by waiting for captain expectations and daily loss value is calculated, as can be seen from the above theoretically calculated parameters optimization before too many orders every day and refused to customer loss value reached 69120 yuan, and the average waiting time of customers achieve nearly ten minutes. These two important parameters are compared with the optimization strategy to select the most reasonable optimization strategy.

Strategy 1 does not invest too much compared to before the improvement, but only USES the method of program analysis in industrial engineering to remove some unnecessary production processes and combine some similar production processes. The loss value of strategy 1 is 13,680 yuan per day, and the average waiting time of customers is 2.28 minutes. This strategy can achieve such great optimization effect without a large amount of capital investment.

Strategy 2 has undergone two changes on the basis of the improvement, so it is more troublesome to compare strategy two with the improvement. So I directly compared strategy two with strategy one and calculated from the previous section that the daily loss value of strategy two was 720 yuan. From this, it can be calculated that the difference of loss value between strategy 1 and strategy 2 in a year is (ten thousand yuan), among which 300 days are the working days of the company in a year excluding various holidays
[1] Xiong Junxing, Zhao Jinping, Zhang Qing, Liu Jiansheng. Analysis and optimization of queuing problems in supermarket cashiers [J]. High Technology Letters, $2019,29 \quad(02)$ : 189-194. DOI: 10.3772/j.issn.1002-0470.2019.02.010

[2] Zhang Xuelong. Research on optimization of enterprise production process based on process analysis method [J]. Industrial Engineering and Management, 2012, 17 (01): 40-45. DOI: 10.3969/j.issn.10075429.2012.01.008

[3] Gao Liuyan, Ma Hanwu, Li Yujiang, Yao Xiangyi. Analysis and improvement of rubber wheel production process based on value flow chart [J]. Machinery Design and Manufacturing, 2019 (10): 269-272. DOI: 10.19356/j.cnki.1001-3997.2019.10.068

[4] HUANG N D, BI Q Z, WANG Y H et al.5-Axis adaptive flank milling of flexible thin-walled parts based on the on-machine measurement[J]. International Journal of Machine Tools and Manufacture,2014,84(6):1-8. DOI: 
Machinery Technology and Management, 2013, 7 (11) 95-97. DOI: 10.3969/j.issn. 1004-0005.2013.11.025

[12] Yuan Zhe. Research on single service queue optimization of warehouse robots under the condition of throughput determination [D]. Huazhong University of Science and Technology, 2015. DOI: CNKI: CDMD:2.1015.909644

[6] Chen Sha, Xia Li. A review of research on pricing control of queuing system [J]. Control Theory \& Applications, 2018, 35 (01): 41-55. DOI: 10.7641/CTA.2017.70066

[7] SO K C, SONG J S Price, delivery time guarantees and capacity selection[J]. European Journal of Operational Research, 1998, 111 (1) :28-49. DOI: 10.1016/s0377-2217(97)00314-7

[8] MAGLARAS C Revenue management for a multiclass single server queue via a fluid model analysis[J]. Operations Research, 2006, 54 (5) :914-932. DOI: $10.2307 / 25147024$

[9] Wei Yingyuan, Tang Yinghui, Yu Yimiao. The captain distribution and optimal strategy of M / G / 1 queueing system based on $\min (\mathrm{N}, \mathrm{D})$ strategy $[\mathrm{J}]$. System Science and Math, 2015, 35 (06): 729-744. DOI: CNKI: SUN: STYS.0.2015-06-011

[10] Bai Baocang. Production planning and process optimization of refrigerated products in TY enterprises [D]. Guangzhou: South China University of Technology, 2010. DOI: CNKI: CDMD:2.1011.042608

[11] Yu Xinjian, Xu Kelin. Research method of assembly line queuing theory $[\mathrm{J}]$. Construction
[13] Xiong Fangfang. Research on M / M / 1 / N - M / M / c / K queuing system and its application in anchorage [D]. Wuhan University of Technology, 2010. DOI: CNKI: CDMD:2.1011.058557

[14] Wang Qi. Research on Outpatient Process Optimization Based on Queuing Theory and Business Process Reengineering Theory [D]. Huazhong University of Science and Technology, 2008. DOI: CNKI: CDMD:1.2009.044695

[15] Zou Xuehua, Yu Miaomiao, Tang Yinghui, Zhou Jie. Numerical calculation of the distribution function of customer stay time for M / G_N / 1 personalized service queue based on feature root method [J]. Journal of Operations Research, 2018,22 (01): 97-108. DOI: 10.15960/j.cnki.issn.1007-6093.2018.01.008

[16] Tang Yinghui, Lan Shaojun. Non-strategy and Min $(\mathrm{N}, \mathrm{V})$-strategy $\mathrm{M} / \mathrm{G} / 1 / \infty$ queueing system waiting time random decomposition structure [J]. System Engineering Theory and Practice, 2016,36 (1): 174-183. DOI: 10.12011 / 1000-6788 (2016) 01-0174-10. 